\title{
Challenges of Men in Early Childhood Education
}

\author{
—Case Study of an American Male Early Childhood Teacher
}

\author{
Yan Yang, Ed.D. \\ School of Education \\ Shanghai Normal University Tianhua College \\ Shanghai, People's Republic of China 201815 \\ Email: peggyhelen@163.com
}

\begin{abstract}
Early childhood education is recognized as a gender-atypical occupation for men, so men who choose to teach at this level are often under public suspicion and scrutiny. This paper focuses on the experiences of an American male early childhood teacher for an in-depth understanding of the nature of his experiences. Semi-structured intervie ws were conducted with the participant to elicit his perspectives. Moreover, data of observation and document review were also provided to guarantee the credibility of the findings. It was found that the participant was confronted with many challenges in his interaction with female colleagues, parents and students. Further, these challenges were deeply rooted in traditional gender norms of the culture.
\end{abstract}

Keywords-early childhood education; gender; masculinity; challenge

\section{INTRODUCTION}

Traditional social norms dictate that men demonstrate masculine characteristics while women possess feminine traits in work and life. Men and women possess combinations of masculine and feminine traits, but men who demonstrate overtly feminine traits are vulnerable to the risk of gender stigma [1].

Early childhood education has been universally recognized as a feminized profession [2]. How can a man do the job of nurturing, teaching and caring for young children? Entering a feminized profession will earn a man nothing but confused looks from friends and suspicion from some of the parents [3]. Stigmata can be assigned to anyone whose behaviors are against what people commonly expect [1].

To make things worse, there is strong evidence to suggest that many parents or guardians are concerned when their young children are assigned a male teacher [4]. Men who enter the teaching profession, particularly early childhood teachers, are highly expected to "fulfill normative gender roles; to perceive some social exclusion by female colleagues; to be acutely aware of the risk of allegations of child sexual abuse" [4]. These expectations make male teachers feel that they are under suspicion and great pressure at workplace.

Exposed to high risk of gender stigma combined with the surveillance and suspicion of parents and guardians, male early childhood teachers may either continue with involvement and develop coping mechanisms for the stigma, or quit to avoid association and stigma, which is referred to as disidentification [5].

As a teacher who once taught students majoring in early childhood education, I have got opportunities to establish close relationships with them. Male students were obviously outnumbered by a sea of female students. After graduation, some of them chose not to teach or chose to quit teaching after one-year work as a male kindergarten teacher. In conversations with them, my research interests arose. Even today, the early childhood education profession is still a largely female world, as is evidenced by scarcity of male early childhood teachers. However, male role models are as important as female ones for children at the earliest ages in terms of developing their personalities[3].

By listening to the story of male early childhood teachers, I try to use my research to make them heard by those who have the same experiences, those administrators of kindergarten, and those whose children are nurtured and educated by male early childhood teachers.

The purpose of this research is to give voice to one male early childhood teacher in a feminized profession for an in-depth understanding of his experiences.

The research question is: What are the challenges associated with being a male teacher in early childhood education?

\section{Methodology}

A case study is aimed at better understanding an issue or problem with the case as a specific illustration [6]. Therefore, the focus of this study is on the gender issue explored through detailed description and analysis of one case-An American male early childhood teacher with many years' work experiences.

\section{A. Participant}

I adopted the criterion sampling in locating one potential participant for my study. First, I decided on the inclusion criteria: (1) he teaches at the early childhood level, (2) he is male, and (3) he has taught at this level for over 20 years. Next, I asked some professors of the school where I once studied to recommend some names, and was given the contact information of five male early childhood teachers. Then I wrote to all of them to introduce myself and the focus of the 
study and invited them to join my research as possible respondents.

Two teachers working at different elementary schools replied via email soon and were willing to join my research. After comparing and contrasting their work experiences, I finally chose one as my participant. Then I sent him the informed consent document to sign his name and the interview protocol to review and think about the questions in advance.

Pseudonym is used for the participant throughout the paper. The participant is identified as David in this study. David teaches the second grade at an elementary school in Northern California. His ethnicity is Caucasian. He got his M. A. degree in the teaching of history. He has worked as a teacher for 32 years, with seven years in a private Christian school and the rest in public schools. He is the only male early childhood teachers at his school.

The elementary school where David works is a Title One School, where there are a lot of very poor children. Over 90 percent of the students in the school are very poor. They receive funds from the US government, so tuition, lunch, and school bus service are all free. This elementary school teaches kindergarten through the sixth grade.

\section{B. Data Collection and Analysis}

I conducted two one-hour interviews with David in his classroom on campus. In addition, I observed for 45 minutes in the reading class. Documents I reviewed include the test papers of students, assignments of students, the curriculum guidelines and the pacing guide.

Coding, a typical categorizing strategy, was employed for data analysis with emphasis on relationships of similarity [7]. The significant statements made by the participant were first highlighted and then formulated meanings were given to them. Finally, clusters of the formulated meanings were developed into themes [8].

\section{FINDINGS}

Teachers may confront diverse challenges in their interaction with students, parents and colleagues. Furthermore, as a male teacher, his gender adds to his challenges. David mentioned that many challenges in his work are due to the fact that he is male. The hassles David faces include: daily interaction with the relationship-oriented female colleagues, parents' assumptions about male teachers, and a disciplinarian role he was forced to play.

\section{A. Relationship-oriented Female Colleagues}

David found gender differences in his daily interaction with female colleagues. At school, women usually just talk about teaching with him; after school, women usually hang out together and do a lot of girls' talking. David said:

They don't ever hang out in my classroom. That's probably because I am male, and to hang out in here, people might talk, I suppose. So that's my guess why they don't. If they do come to see me, there is a purpose to it, usually, like for information or they want my thoughts on something, but most of time, it's not like they talk with women, you know. It's different.
David had a feeling of isolation in a sea of relationship-oriented women colleagues and he found it difficult to join them. He stated, "When women want to talk about something that they usually talk about with only girls around, they will say: close your ears, David."

Furthermore, David found that Women were not willing to cause trouble or negatively impact their relationships even if they disagreed with the principals' decisions in the staff meeting. "Instead, women will talk about it in small groups afterwards, but they may not take the risk. Later on, they will say: 'I am so glad you brought that up'."

\section{B. Parents' Assumptions}

David pointed out parents' assumptions about male teachers. Parents of students were worried about their children if they know their babies were assigned to a male teacher's class. David said, "On the first day of school, I always have parents who are afraid to have their children in my class because I am a man, and they think I am going to be too strict, too hard on their little babies."

Furthermore, parents' assumptions about male teachers mostly focus on the issues of physical contact. He learned about the suspicions about male teachers' physical touch with young children when he was in his credential program, so he chose to do something else to compensate for lack of physical touch with his students. David stated:

Oh, my Goodness! Doing this job means you need to give your fingerprint to FBI. Because of the gender, I always have to safeguard myself as far as touching a kid. I leave my door open during the tutoring after school. If it comes to a kid who wants to hug me, I do a high five or kind of a side hug, because I never want it said that, you know, it is a sexual thing.

\section{A Disciplinarian Role}

David was forced to play the role of a disciplinarian by either school administrators or his female colleagues. As a male teacher, he was expected to act as the disciplinarian in class, especially in a class of boys with many behavioral problems. David explained:

I find from the administration that they often feel that if they get a tough child who registers for school, they dump him in my class, because male teachers are going to be the disciplinarian. So I have had many challenging years. This year is a lucky year for me, because this is my first year in a dozen of years where I have a nice mix of students [at different levels of performing]. Usually, I have many lows and few mediums and a lot of behavioral issues.

In my observation of his class, although students were academically balanced and there were more girls than boys, David still needed to keep calling students' attention. "Are you off task?”, “I don’t want to hear you.”, "Back to work.”, "Get to your work." and words like these were used to call students' attention continually. I heard these words six times within 15 minutes. 


\section{DISCUSSION}

As noted earlier, early childhood education, as a female-dominated profession, will earn a male teacher suspicions from some of the parents [3]. In this study, David suffered parents' stereotypical assumptions about male teachers. This finding also aligned with the argument made by Sumsion [4] that many parents or guardians are concerned when their young children are assigned to a male teacher. Moreover, Consistent with Sumsion's [4] study, David, as a male early childhood teacher, was highly expected to fulfill normative gender roles; to perceive some social exclusion by female colleagues. As a result, David felt troubled by these expectations in the workplace. In addition, male teachers are expected "to be acutely aware of the risk of allegations of child sexual abuse" [4], which was echoed by this study that David always had to safeguard himself as far as having physical contact with his young students.

\section{A. Limitations}

There are several limitations of this study. First, only one participant was involved in this study. A larger number of participants could add more details and depth of understanding regarding what it means to be male early childhood teachers. Second, the participant was observed only once. More information could be collected with more observations. Third, due to the cursory nature of the literature review, the discussion of the findings in relation to the literature is limited.

\section{B. Recommendations for Future Research}

Future research could explore the experiences of male early childhood teachers working in the Chinese culture for the purpose of comparison and contrast with the experiences of American male early childhood teachers. In addition, future research could focus on male teachers' perceptions of their roles in early childhood education. Moreover, further research can be conducted on the issue of male early childhood teachers' long-term professional development.

\section{CONCLUSION}

This study explores the gender issue through in-depth description of one experienced American male early childhood teacher. This study raises the issue of gender inequity in early childhood education, which is widely recognized as a feminized occupation. Men are expected to demonstrate hegemonic masculinity by pursuing more ambitious occupations. These gender stereotypes contribute to gender inequity in early childhood education, and give rise to many challenges for male teachers.

\section{REFERENCES}

[1] D. L. Schmalz, and D. L. Kerstetter, "Girlie girls and manly men: Children's stigma consciousness of gender in sports and physical activities," in Journal of Leisure Research, vol.4, 2006, pp. 536-557.

[2] M. Mills, M. Haase, and E. Charlton, "Being the "right” kind of male teacher: the disciplining of John,” in Pedagogy, Culture \& Society, vol.1, 2008, pp. 71-84.

[3] S. Friedman, "Male voices in early childhood education and what they have to say about...., " in Young Children, vol. 3, 2010, pp. 41-45.

[4] J. Sumsion, "Negotiating otherness: a male early childhood educator's gender positioning, ” in International Journal of Early Years Education, vol. 2, 2000, pp. 129-140.

[5] C. M. Steele, "A threat in the air: How stereotypes shape intellectual identity and performance," in A merican Psychologist, vol. 6, 1997, pp. 613-629.

[6] M. Q. Patton, Qualitative Research \& Evaluation Methods, 3rd ed., Thousand Oaks, CA: Sage Publications, 2001.

[7] J. A. Maxwell, Qualitative Research Design: An Interactive Approach, 3rd ed., Thousand Oaks, CA: Sage, 2012.

[8] J. W. Creswell, Qualitative Inquiry and Research Design: Choosing Among Five Approaches. Thousand Oaks, CA: Sage, 2012. 